IZA DP No. 8140

La Meglio Gioventù:

Earnings Gaps across Generations and Skills in Italy

Paolo Naticchioni

Michele Raitano

Claudia Vittori

April 2014 


\title{
La Meglio Gioventù: Earnings Gaps across Generations and Skills in Italy
}

\author{
Paolo Naticchioni \\ University of Roma Tre \\ and IZA \\ Michele Raitano \\ Sapienza University of Rome and \\ Giacomo Brodolini Foundation \\ Claudia Vittori \\ Sapienza University of Rome \\ and University of Bath \\ Discussion Paper No. 8140 \\ April 2014 \\ IZA \\ P.O. Box 7240 \\ 53072 Bonn \\ Germany \\ Phone: +49-228-3894-0 \\ Fax: +49-228-3894-180 \\ E-mail: iza@iza.org
}

Any opinions expressed here are those of the author(s) and not those of IZA. Research published in this series may include views on policy, but the institute itself takes no institutional policy positions. The IZA research network is committed to the IZA Guiding Principles of Research Integrity.

The Institute for the Study of Labor (IZA) in Bonn is a local and virtual international research center and a place of communication between science, politics and business. IZA is an independent nonprofit organization supported by Deutsche Post Foundation. The center is associated with the University of Bonn and offers a stimulating research environment through its international network, workshops and conferences, data service, project support, research visits and doctoral program. IZA engages in (i) original and internationally competitive research in all fields of labor economics, (ii) development of policy concepts, and (iii) dissemination of research results and concepts to the interested public.

IZA Discussion Papers often represent preliminary work and are circulated to encourage discussion. Citation of such a paper should account for its provisional character. A revised version may be available directly from the author. 


\section{ABSTRACT \\ La Meglio Gioventù: \\ Earnings Gaps across Generations and Skills in Italy}

This paper documents the evolution of the experience-earnings profiles of private employees in Italy over the first six years of working career across three birth cohorts (1965-1969, 1970$1974,1975-1979)$. We explore the average trends and disentangle how the patterns vary according to individual skills, defined in terms of both educational levels and percentiles of the unconditional earnings distribution. Unlike previous studies, and in contrast with the expectations prompted by the skill-biased literature, our results surprisingly show that the Italian "best of youth", i.e. the best workers of the most recent cohorts (the high skilled), have suffered, compared to the previous cohorts, an earnings penalty much more severe than that experienced by unskilled workers. This finding also raises questions about the effectiveness of the European Employment Strategy, which repeatedly stressed the importance of human capital and technological knowledge as main drivers for European performance.

JEL Classification: J24, J31

Keywords: $\quad$ youth, cohorts, education, earnings, Italy

Corresponding author:

Paolo Naticchioni

Roma Tre University

Faculty of Economics

Via Silvio D'Amico 77

00154 Rome

Italy

E-mail: p.naticchioni@gmail.com

\footnotetext{
"Reference is to the Italian film "La Meglio Gioventù" (2003), entitled in the English version "The Best of Youth". The movie tells the story of an Italian family, their children and friends, from the years of youth in the '60s to university studies, working career, parenthood, and retirement in the 2000 s.

Preliminary versions of this paper were presented at the 5th ECINEQ meeting in Bari, at the XXV AIEL conference in Rome and to a workshop organized by ISFOL and Sapienza University of Rome. We wish to thank participants in these conferences for useful suggestions and comments. The usual disclaimer applies. Michele Raitano also thanks Giacomo Brodolini Foundation for access to the ADSILC dataset.
} 


\section{Introduction}

There has been increasing concern amongst academics and in public opinion about the dwindling of labour market opportunities for young workers across Europe. Figures from Eurostat (2013) showed that by the end of 2013 in EU28 youth unemployment had reached over $23 \%$. In some EU countries, such as Italy, which is the focus of this paper, the plight of young people is even more worrying. The unemployment rate is almost twice the 2013 European figure, reaching 40\% amongst those aged 15-24. The 25-29 employment rate in 2012 was $57.3 \%$ against $71.1 \%$ in the EU28, and the Not in Education, Employment and Training (NEET) rate was $23.9 \%$ in contrast with a EU28 value of $15.8 \%$.

In such a state of affairs, commentators started to refer to the recent generation as génération sacrifiée, zero generation, postponed generation, the "1000 euro" generation and the Status Zero Youth. The UK press (Financial Times, Nov. 2013) refers to them as the "lost generation", due to their sharp fall in earnings starting from their early career, compared to their pre-crisis counterparts at the same stage.

The sociological literature has extensively studied the conditions of the young generations along several dimensions, i.e. educational attainments, occupational paths, social mobility, life courses and transitions to adulthood (e.g. see Blossfeld et al. 2005 and 2008 for cross countries comparisons, Schizzerotto et al. 2011 for the Italian case). The literature on occupational paths focuses mainly on labour market entry, in terms of first job search duration, the quality of the first job, and the early career path, assessed in terms of unemployment risks and transitions among different contractual arrangements (Bukodi et al. 2008). However, to the best of our knowledge, none of the studies has explored labour incomes trends across generations.

The economic literature, on the other hand, has devoted limited but growing attention to analysis of earnings patterns across generations in some OECD countries. Beaudry and Green (2000) and Beach and Finnie (2004) find a declining entry wage for those who entered the labour market during the '90s in Canada (by 10-15\%) in contrast with steady upward shifts in the earnings profiles for the '60s and '70s cohorts. In Germany the picture is quite different: the earnings of the young cohorts grew at the same rate as those of other cohorts over the period 1976-1984 (Fitzenberger et al. 2001).

Another stream of the literature explored the dynamics in earnings across generations to understand changes in inequality over time. Gosling et al. (2000) show that one third of the overall rise in wage dispersion in the period 1966-1994 in the UK is due to a drop in median wages of successive cohorts entering the labour market. For the US, Card and Lemieux (2001) reveal that the increase in inequality might be at least partially accounted for by a cohort 
effect: over the period 1956-1995 wage skill premia increased, but substantially more for men in their early thirties (it doubled) than for older men.

As for Italy, Rosolia and Torrini (2007 and 2013) offer preliminary evidence on the deterioration of entry wages over the 190 s compared to older generations. Using administrative data, they find that younger generations experience a permanent loss in their working life earnings due to a lower entry wage, which is not offset by a faster career. ${ }^{1}$

The main contribution to the literature offered by our paper is to show that in Italy the deterioration of the earnings dynamics in the early phase of the career has not been homogenous across skill levels. The previous literature either finds no significant heterogeneity among differently skilled workers or simply fails to investigate the heterogeneity across skills. In Germany the wages of young workers with intermediate education levels deteriorated slightly compared to those of both high and low educational levels (Fitzenberger et al. 2001). In the US a loss of earnings power among younger non-college educated workers - compared to their previous counterparts - is documented by Mishel (2012), while in Canada no differences in the earnings patterns of upper secondary and tertiary educated workers emerged (Beadry and Green 2000). ${ }^{2}$

We make use of a very rich panel dataset, AD-SILC, recently built merging information from the Italian sample of the Survey on Income and Living Condition (IT-SILC) for 2005 with information collected from administrative archives managed by the Italian Social Security Institute (INPS). This dataset enables reconstruction of the whole working history of the individuals observed in the IT-SILC sample and allows us to gather information on a wide set of individual characteristics and in particular education, known to be one of the main determinants of earnings.

We estimate the earnings-experience profiles at the beginning of the workers' careers in Italy over the period 1980-2009 for individuals belonging to 3 different birth cohorts: 1965-1969, 1970-1974 and 1975-1979. We follow their working careers from the year of labour market entry to their $6^{\text {th }}$ year of labour market experience. We then observe the individual earnings path in the period 1980-2009, up to the beginning of the current deep economic recession. ${ }^{3}$

\footnotetext{
${ }^{1}$ They use data from the Italian Social Security Institute (INPS) or Bank of Italy (SHIW). The 2013 paper is an updated version of the 2007 paper with data up to 2010.

2 As for Italy, Rosolia and Torrini (2007 and 2013) data do not record individual education. They imperfectly proxy the educational attainment using the observed labour market entry age (considering only those who entered at 21-22 and 25-26) and find a widening wage gap between younger and older workers for all groups of workers, irrespectively of their labour market entry age.

${ }^{3}$ Our findings do not change when the time period is restricted to 1980-2007, i.e. before the beginning of the current crisis.
} 
We estimate a simple model to identify the components of annual earnings dynamics that are cohort specific and experience specific, while controlling for workers characteristics (e.g. gender, education, region of work) and for business cycle (proxied by GDP growth and regional unemployment rates). In this way we obtain an estimate of the average wage profile in the first six years of their career for workers belonging to different cohorts.

We use two different measures of skills. First, we take into account educational levels. Second, we perform unconditional quantile regressions: unskilled, median skilled and skilled workers are identified as those individuals belonging, respectively, to the $10^{\text {th }}, 50^{\text {th }}$ and $90^{\text {th }}$ percentile of the unconditional earnings distribution.

Our study highlights a deterioration of the earnings dynamics in the early phase of the career for the most recent cohorts compared to the older ones, and it reveals that the high skilled workers are particularly penalized.

More in detail, the OLS estimates by educational levels show that the cumulative earnings difference between the youngest and the oldest cohort of tertiary graduates in the first six years of their working life amounts to around $€ 35,500$. These differences are lower for upper secondary educated workers, accounting for $€ 16,600$, and are much more limited $(€ 2,800)$ for those with at most a lower secondary degree. Interestingly, we obtain very similar findings when using unconditional quantile regressions as proxy for skills.

Unlike previous studies for Italy and for other countries, and in contrast with the expectations suggested by the skill-biased literature (Katz and Autor 1999), our results show, surprisingly, that the Italian "best of youth", i.e. the best workers of the most recent cohorts (the high skilled), have suffered, compared to the previous cohorts, an earnings penalty much heavier than experienced by the unskilled workers. From a policy point of view, this is even more surprising considering that since the Lisbon Summit of 2000 the European Employment Strategy repeatedly focused on the very ambitious goal of becoming the most dynamic knowledge-based economy, stressing the importance of human capital accumulation and innovation. Our findings suggest this is not the case for the most recent cohorts of graduates entering the labour market.

The paper is organized as follows. Section 2 outlines the main trends and institutional changes that have characterized the Italian labour market since the '80s. In section 3 the characteristics and the main pros of the AD-SILC dataset are discussed and the empirical strategy is presented in section 4. Section 5 includes the main results of the empirical analyses: descriptive evidence (section 5.1); OLS estimates of the baseline model (section 5.2); alternative 
OLS specifications (section 5.3); unconditional quantile regressions (section 5.4). Finally, section 6 concludes with some remarks on possible determinants of the patterns observed.

\section{The Italian framework}

As pointed out in the introduction, Eurostat data suggest that the prospects of young generations seem to be very worrying as far as Italy is concerned. It is important to note that the low youth employment rates cannot be attributed to high university enrolment rates: Italy is in fact characterized by the highest share of NEET in the EU (after Greece and Bulgaria). In addition, even though the share of the young population enrolled in tertiary education in Italy is no higher than the EU average, Italians start work relatively later: the majority start work at the age of 23, while in most of the other countries the usual entry age is 20 (Eurostat 2009). ${ }^{4}$

Italy has also been characterized by an almost flat trend in mean real earnings associated with very slow productivity growth rates. ${ }^{5}$ On average, private employees' real earnings remained substantially constant since 1995, after a steady increase during the '80s and a sudden decline due to the 1992-1993 economic downturn (Raitano 2012). Moreover, analysing the earnings patterns in Italy over the last decades, two main set of institutional changes need to be taken into account.

First, in order to stop the wage-price spiral, the automatic indexation mechanism (the scala mobile) was weakened in 1984 and finally abolished in 1992. Subsequently, a new agreement among the social partners on wage bargaining (the 23rd of July 1993 Protocol) established that the renewal of national collective contracts had to refer to the programmed inflation rate rather than to the expected inflation rate.

Second, since 1997 the Italian labour market has been characterized by a series of institutional changes. ${ }^{6}$ After the occupational crisis of the early '90s, a series of reforms (the main ones phased in 1997, 2001, 2003) has been put forward with the aim of reducing labour market rigidity, often considered one of the main causes of the high unemployment rates (OECD 1994). These reforms introduced several new types of flexible contractual arrangements, thus increasing the probability to hire employees through fixed-term and atypical arrangements. The process of labour market deregulation has been defined "partial and targeted" (Esping

\footnotetext{
4 Although educational attainments have increased in Italy over the last few decades, the share of tertiary graduated among the workers aged 25-64 is currently still much lower than the EU28 average (19.4\% versus $34 \%$; Eurostat data) while the share of those having at most a lower secondary degree is much higher (34.2\% as against $21.7 \%$ ).

${ }^{5}$ As reported by the OECD, in Italy the average annual labour productivity growth rate amounted to $0.2 \%$ in the period 1997-2008 (0.9\% in the Euro area), while it amounted to $2.0 \%$ in the period $1986-1996$ in Italy.

${ }^{6}$ For a detailed description of the Italian labour market reforms see Berton et al. (2012).
} 
Andersen and Regini 2000), as the new flexible arrangements mostly applied to new entrants in the labour market (Blanchard and Landier 2002). As argued by Barbieri and Scherer (2009), labour market flexibilization engendered negative consequences for the young generations, in terms of both employment stability and welfare guarantees.

\section{Dataset}

Analysis of earnings trends across cohorts requires the use of long panel dataset. The evolution of the earnings distribution in Italy has been studied mainly using microdata provided by the Survey on Household Income and Wealth (SHIW), which has been carried out every two years by the Bank of Italy since the '70s and contains a very small panel component (Brandolini et al. 2001). The time span covered by similar surveys at the EU level is instead limited. At present, the ECHP covers the period 1994-2001 and the EU-SILC refers to the period 2004-2011.

Actually, a great deal of longitudinal data are collected into the administrative archives managed by the Italian National Social Security Institute (INPS), which record gross earnings and the number of related working weeks for each working episode in each year. However, these archives record only the information needed for administrative purposes. In particular, the INPS data - used by Rosolia and Torrini (2007 and 2013) - do not record individuals' education, which is, of course, a crucial determinant of earnings.

This limitation has recently been overcome merging the IT-SILC 2005 sample (i.e. the Italian version of EU-SILC 2005, carried out by ISTAT), that reports the value at 2005 of dozens of individuals' characteristics, with the administrative records on individual working histories from labour market entry up to 2009. Therefore, this new retrospective panel dataset - called AD-SILC - is the first source that allows following individual working histories since the past decades for a large sample of Italian workers.

On the one hand, with the administrative sources it is possible to reconstruct for each individual the time of labour market entry, the effective labour market experience and annual earnings, and other important covariates such as the region of work, gender, age and information on contractual arrangement (i.e. part-time versus full-time). ${ }^{7}$ On the other hand, through matching with the survey data we can add information on educational attainment using three dummy variables indicating the highest degree achieved: at most lower secondary (ISCED 1-2), upper secondary (ISCED 3) and tertiary or post-secondary (ISCED 4-6).

\footnotetext{
7 Information on fixed-term contracts has only been available since 1998. Employers' characteristics (e.g. firm's size and sector) have been recorded since 1987 only.
} 
We use AD-SILC data to assess the evolution of the earnings patterns in the beginning phase of working careers. More in detail, we group individuals according to their birth year in 3 cohorts - 1965-1969, 1970-1974 and 1975-1979 - and we follow their working careers from labour market entry year up to the end of their $6^{\text {th }}$ year of labour market experience. ${ }^{8}$ We then observe the individual earnings paths in the period 1980-2009.

Our main variable of interest is earnings from private employment. ${ }^{9}$ More in detail, we analyze the trend of private employees' annual real gross earnings in Euros (annual earnings have been converted to 2010 constant prices using the consumer price index). ${ }^{10}$ The reason why we restrict our attention to private employee's earnings is twofold: i) self-employed incomes are plagued by huge problems of underreporting and truncation in the administrative archives; ii) earnings of public employees, parasubordinate workers and professionals have been available only since 1996 .

Hence, the final sample comprises 35,904 observations concerning 7,504 private employees born in the period 1965-1979.

\section{Empirical strategy}

We begin with an accurate analysis of the descriptive evidence (section 6.1), and proceed by means of two methodologies: i) estimating mean earnings profiles through OLS regressions (sections 6.2 and 6.3); ii) estimating the trends at different points in the earnings distribution using unconditional quantile regressions (section 6.4).

The results are presented mainly through figures, which more effectively summarize the descriptive and estimated trends in the first 6 years of the working career. Furthermore, the tables show the values at entry and the sixth year of working career together with some related summary measures of the earnings differences across cohorts. ${ }^{11}$

\footnotetext{
8 We identify the entry year as the first year with a working episode lasting at least 13 weeks and an age no lower than 15. Moreover, we drop from the sample those aged over 30 in the entry year. Note that we exclude from our sample immigrants because the retrospective panel AD-SILC under-represents immigrants in the past decades. Furthermore, we lack information on job search duration before the first job.

9 Therefore, records concerning periods spent as public employees, self-employed or parasubordinates (i.e. individuals formally acting as self-employed but usually working as substitutes of employees) have been used only to measure the total labour market experience of those working as private employees.

${ }^{10}$ In order to reduce the impact of outliers we dropped from the sample, in each year, the top and bottom $1 \%$ of the earnings distribution.

11 When we explore trends in annual earnings we exclude the first year of experience because workers may start at different times of the year and so their yearly earnings cannot be comparable with yearly earnings in the following years. Hence, we consider as the starting year the second year of labour market experience. This does not apply to weekly wages, for which we also can consider the entry year.
} 
The descriptive evidence refers to sample means of the gross annual earnings of private employees computed - separately for the three cohorts - in the six working years following the entry year, also distinguishing workers according to their level of education.

However, descriptive plots should be taken with caution for two main reasons. First, they do not take into account change in the labour force composition over time, e.g. change in individual characteristics such as increase in educational attainment and female participation. Second, they do not account for business cycle effects on the patterns characterizing different cohorts at different seniorities (i.e. years of experience) in the labour market. Thus, in the second step of our empirical analysis, we move to estimate, through OLS, average earnings profiles to take into account both individual observed heterogeneity and business cycle.

In order to estimate mean earnings dynamics, our baseline model is as follows:

$$
\begin{aligned}
& w_{i j t}=\beta_{j}{ }^{*} \text { Cohort }_{j}+\gamma_{j}{ }^{*} \text { Experience }_{i j t}{ }^{*} \text { Cohort }_{j}+\delta_{j}{ }^{*} \text { Experience }_{i j t} \wedge 2{ }^{*} \text { Cohort }_{j} \\
& +\eta_{j}{ }^{*} \text { Experience }_{i j t} \wedge 3 * \text { Cohort }_{j}+X_{i j t}^{\prime} \gamma+\varepsilon_{i j t}
\end{aligned}
$$

where $w_{i j t}$ stands for our dependent variables, individual annual (log) earnings (where $i$ is the individual, $j$ the birth cohort and $t$ the year). The time earning dynamics is captured using for each cohort an intercept for the entry level and a trend for the first six years of career. Hence we include as covariates the three birth cohort dummies, to allow for different intercepts, and the interaction terms between the three cohort dummies and the labour market experience (see equation 1). In order to capture possible non-linearities we make use of the third degree polynomial in labour market experience. Therefore, estimated mean earnings along the first six years of the working life are computed for each cohort adding the predicted value of the third grade polynomial to the cohort specific $\beta_{j}$ coefficient.

A wide set of control variables $X_{i t}$ is included: individual characteristics - gender, education and work region dummies - and proxies of the business cycle, i.e. the GDP real growth rate in the previous year and the current regional (NUTS-2) unemployment rates, both included through a third-order polynomial.

We also investigate whether the results are affected by unemployment spells during the year by running OLS regressions using as dependent variable the logarithm of weekly wages (computed dividing annual private employment earnings by the number of weeks worked as a private employee during the year) and including among the covariates a dummy variable for part-time jobs, which has been proved to affect unemployment risks (Booth et al. 2002).

As a further robustness check, we change our baseline model considering as dependent variable the ratio between the individual annual gross earnings and the mean annual earnings 
of prime-age private employees (i.e. those aged 35-44 in the full AD-SILC sample), with the aim of further depurating patterns specific to the first phase of the career from trends common to all private employees. Moreover, we investigate trends by gender and parental background. One of the main original contributions offered by the paper consists in carrying out our analysis by education level. An alternative way of capturing possible heterogeneity in skills is to estimate unconditional quantile regressions, as proposed by Firpo et al. (2009). By using this methodology it is possible to estimate a given percentile of an unconditional distribution of earnings applying the same specification used with OLS for average wages. The goal of this step is, therefore, to endow the analysis by skills with robustness.

More specifically, the basic idea behind the unconditional quantile regressions is to estimate a linear regression where the dependent variable $Y$ is replaced by the Recentered Influence Function (RIF) of the distributional parameter $v, \operatorname{RIF}(y ; v)$. The RIF is obtained by adding the distributional parameter concerned to the influence function $I F(y ; v) .{ }^{12}$ A useful property of the $\operatorname{RIF}(y ; v)$ is that its expected value is the statistic of interest. Hence, applying the law of iterated expectations, it is possible to write:

$$
v=E[R I F(Y ; v)]=E_{X}\{E[R I F(Y ; v) \mid X]\}
$$

In its simplest form, the conditional expectation of the $\operatorname{RIF}(y ; v)$ can be written as a linear function of the covariates, yielding the RIF regression (Firpo et al 2009):

$$
E[R I F(Y ; v) \mid X]=X \gamma^{y}
$$

where the parameters $\gamma_{t}^{v}$ can be estimated by OLS. The parameter $v$ can be any distributional parameters, such as the Gini index, the variance or the percentiles of the wage distribution. Extension to the percentiles of the wage distribution was proposed by Firpo et al. (2009). In such a way it is possible to write the percentile of distribution as a function of the set of covariates $\left(v=E[R I F(Y ; v)]=E_{X}\{E[R I F(Y ; v) \mid X]\}\right)$, thus isolating the contribution of the variables we are interested in (cohort and labour market experience), as we did for average wages.

It is worth stressing the importance of using unconditional quantile regressions instead of the standard conditional quantile regressions (Koenker and Basset 1978): when using conditional quantile regressions, for instance at the median, the estimates refer to the median of the "error term", whereas by using unconditional median quantile regressions it is possible to recover the

12 The influence function (Hampel 1974) is a statistical tool, used to assess the robustness of a distributional statistic to the presence of outliers. 
impact of the covariates on the median of the unconditional distribution, which is what we are interested in.

From the practical point of view, we estimate by OLS the RIF regressions for the $10^{\text {th }}, 25^{\text {th }}, 50^{\text {th }}$, $75^{\text {th }}$ and $90^{\text {th }}$ percentiles of the yearly private employees logarithms of gross annual earnings on the same set of covariates used in the baseline model when estimating average earnings. In this way we can isolate the contribution of the different cohorts and of the labour market experience in the first 6 years of workers' careers.

\section{Empirical findings}

\subsection{Descriptive Evidence}

This section offers a descriptive picture of the average "raw" earnings experience profiles for the whole sample of individuals and by educational levels. Figure 1A shows for each cohort the entry earning and the experience profile during the first six years of the working career. As mentioned, entry earnings are computed at the second year of experience, since in the first year individuals enter the labour market at different times.

From Figure 1A it clearly emerges that entry earnings and experience profiles have been deteriorating for more recent cohorts in comparison with older ones. At all levels of labour market experience the three cohorts show consistent ordering: the oldest cohort earns more and the youngest cohort earns less. In particular, those born in the period 1975-1979 have entry earnings 5.8\% lower than the entry earnings of the 1965-1969 cohort. Interestingly, the gap persists over time, and amounts to $4.2 \%$ in the sixth year. Therefore, as also documented by Rosolia and Torrini (2007 and 2013), the youngest Italian cohorts experience a persistent loss in their initial working life earnings, due to a lower entry wage which is not offset by a steeper wage profile.

\section{Figure 1A-1D here}

The picture becomes further worrisome when considering the differences in the generation gaps by educational attainments (Figures 1B-1D). At the level of those attaining at most a lower secondary degree, the differences across cohorts are almost negligible, especially at the end of the observation period (Figure 1B). On the contrary, when considering individuals with upper secondary and tertiary education (Figure 1C and 1D, respectively), the last two cohorts are clearly characterized by the worst entry earnings and experience profiles. With regard to 
the upper secondary educated, the earnings profiles are parallel, but the absolute levels steadily decline across cohorts. As for graduates, the differences between the 1965-1969 cohort and the two following cohorts widen along the first part of the working career. Considering the first six years of experience, the cumulated earnings of the two youngest cohorts are around 13\% (17,000 Euros) lower than the earnings of the oldest cohort (Table 1)

\section{Table 1 here}

\subsection{OLS estimates}

To control for the changing composition of the labour force and for the business cycle, we resort to a regression framework. Figures 2A-2D show the estimated trends relative only to the cohort and experience variables, obtained using OLS estimates of the baseline model (see equation 1). For the sake of comparison, all the values are expressed relatively to the earnings in the second year of experience of the oldest cohort (1965-1969).

A preliminary look at the graphs confirms the evidence of the descriptive analysis: the youngest generations are worse off, and this is particularly evident among the high skilled. From Figure 2A and Table 2 it emerges that, on controlling for business cycle and individual characteristics, the entry earnings of the youngest cohort (1975-1979) are 11\% lower than those of the oldest cohort (1965-1969). The trends across cohorts along the experience profile are then quite similar to those of the entry earnings, the lines being basically parallel to one another, especially for the oldest and the youngest cohort. When we consider the "cumulated" differences across cohorts of the total earnings along the six years of experience, it emerges that the second and third cohorts have lost, respectively, $€ 4,866$ and $€ 8,133$ compared to the first one (Table 2). This cumulative difference is substantial, considering, for instance, that the average entry earning for an individual of the youngest cohort is around $€ 13,000$.

\section{Figures 2A-2D here}

We now focus attention on the predicted trends for individuals with different educational attainments (Figures 2B-2D and Table 2). As for the unskilled workers, i.e. those with at most lower secondary education, the entry earning of the youngest cohort is $6.4 \%$ lower than that of the oldest cohort. These differences dwindle along the experience profiles, ending up with very similar earnings at the sixth year of experience. The fact that the curves get closer implies 
that the cumulative differences across cohorts are smaller for unskilled individuals; indeed, the total loss for the second and third cohort amounts to $€ 2,076$ and $€ 2,800$, respectively (Table 2).

Figure 2C refers to individuals with upper secondary education. Differences across cohorts are straightforward, with a clear deteriorating trend from the oldest cohort, which displays the highest entry earning and the highest earnings along the experience profile, to the youngest cohort, which shows a 15\% lower entry earning and a gap that remains basically constant along the experience profile. The cohort 1970-1974 displays an intermediate position. Such profiles entail substantial cumulative differences with respect to the oldest cohort, respectively amounting to $€ 9,100$ for the second cohort and to $€ 16,743$ for the youngest cohort. This is quite striking if we take into account the fact that the entry earnings for an individual with upper secondary education in the youngest cohort come to $€ 13,500$.

As for tertiary educated individuals, the differences are even wider. Figure 2D and Table 2 reveal that the entry earnings of the youngest cohort is $21 \%$ lower than that of the oldest cohort, and that these differences show even greater increase by the end of the experience profile. Interestingly, among tertiary graduates the second cohort profile comes closer to that of the youngest than to the oldest cohort. These significant gaps produce cumulative differences across cohorts that are striking, as the total losses in the first six years of career amount to $€ 28,973$ for the intermediate cohort and $€ 35,534$ for the youngest (Table 2). Since the average entry earnings for a graduate in the youngest cohort come to $€ 17,750$, this means that the cumulated loss in the first part of the working career amounts to twice the entry yearly earnings.

\section{Table 2 here}

For additional evidence of the relative decline in the earning-power of skilled workers in the youngest cohorts, we can compute educational wage premia through an OLS regression on both (logs of) annual and weekly earnings, with standard Mincerian controls. ${ }^{13}$ Educational wage premia largely decrease for those born in the 170s, especially when annual earnings are considered (Figure 3): indeed, the yearly earnings premia for tertiary graduates decrease from $58.1 \%$ for the oldest cohort to $35.9 \%$ for the youngest.

\footnotetext{
13 The control variables are: gender, a third order polynomial on labour market experience, the three dummies on education (at most lower secondary is the omitted category) and year and region of work dummies. Consistently, Naticchioni et al. (2010), using a different dataset, show falling education wage premia for Italy through both OLS and conditional quantile regressions.
} 


\section{Figure 3 here}

\subsection{Further specifications}

For preliminary robustness verification we make use of the weekly gross real wages instead of the yearly gross real earnings. This is important since penalties in yearly earnings for the younger cohorts might depend on different degrees of labour market attachment, in terms of both weeks worked per year and hours worked per week. In turn, labour market attachment might depend on labour markets reforms that have mostly affected the youngest cohorts in our data. To address this issue we simply use as dependent variable the weekly wage (computed dividing the annual earnings by the weeks worked) instead of the yearly earnings. We include among the regressors a dummy for part-timers (hours worked per week are not available in the AD-SILC dataset; thus it is not possible to compute hourly wages).

Figure 4A shows the career profile for different cohorts. The results are basically confirmed: younger cohorts have lower entry wages and the differences remain basically constant along the first years of career. A point to note is that the penalty for the cohorts born in the '70s is lower when observing weekly wages than when using yearly earnings (respectively, 6.1\% versus $11.2 \%$ at the entry, $7.0 \%$ versus $7.7 \%$ in the sixth year; see Tables 2 and 3 ). This suggests that part of the results obtained for yearly earnings are due to differences in attachment to the labour market of different cohorts. ${ }^{14}$ In any case, a substantial penalty is still there.

When we split the sample according to education level (Figures 4B-4D and Table 3), it emerges that the entry wage penalty for the youngest cohort is still substantial, and slightly increasing over education levels, ranging from $7.8 \%$ for workers with at most a lower secondary degree, to $10.9 \%$ and $10.7 \%$ for workers with upper secondary and tertiary education, respectively. By contrast, the differences observed in the last year (the sixth) grow considerably with education level. For unskilled workers the drop of the youngest cohort compared to the oldest one in the final year amounts to $4.1 \%$, while for workers with upper secondary and tertiary education the drop increases substantially up to around $9.5 \%$, even if it is lower than the gap estimated using yearly earnings as dependent variable (see Tables 2 and 3 ).

This evidence suggests that the deterioration for the youngest cohorts of tertiary graduates does not occur along the remuneration dimension alone, but also in attachment to the labour market, in terms of weeks worked per year and hours worked per week. Indeed, our data

\footnotetext{
14 This evidence is consistent with the findings of the literature on the effect of labour market deregulation in Italy, showing that the young generations who entered the labour market since the mid-' 90 s are more likely to have been employed on atypical and intermittent contractual arrangements. See, among others, Barbieri and Scherer (2009), Berton et al. (2012).
} 
show that the average working weeks per year of tertiary graduates decreased from 49.9 for those belonging to the oldest cohort to 47.6 and 47.0 for those belonging to the cohorts 19701974 and 1975-1979, respectively.

\section{Figures $4 \mathrm{~A}-4 \mathrm{D}$ here}

\section{Table 3 here}

However, a possible limitation to our estimates is that the trends observed could be associated not only with young individuals but with all workers in different cohorts. Basically, it would mean that our specification is not effective in fully controlling for the business cycle, even if it includes GDP growth and regional unemployment polynomials. To respond to this possible critique we derive a new dependent variable, computed as the ratio between the annual gross earnings of young individuals divided by the annual gross earnings of prime-age workers, aged 35-44. In this way we are sure to cancel out all issues related to business cycles, since the new dependent variable is a ratio and the business cycle hits numerator and denominator at the same time.

Also using this "relative earnings" variable our findings are confirmed (Table 4). For all individuals, the entry "relative" earning penalty for the youngest cohort comes to $6.1 \%$. Furthermore, it is increasing along the education levels, amounting to $4.3 \%$ for at most lower secondary educated, $6.7 \%$ for upper secondary educated workers and $8.7 \%$ for tertiary graduated workers. Differences are also persistent along the first six years of the career, becoming particularly notable for workers with tertiary education. Thus the similarities of the results obtained through the baseline specification and the regression on relative earnings between young and prime-age workers clearly confirm that the baseline specification controls appropriately for the business cycle.

\section{Table 4 here}

We also carry out two further specifications in which we investigate differences across cohorts by gender and by parental background for the whole sample (controlling for their education; Table 5).

The gender breakdown confirms that both young males and females are affected by the deterioration in earnings across cohorts. A significant point here is that males suffer a 
substantially greater penalty between the oldest and the youngest cohort, both in the first and in the sixth year of career. Using the cumulate differences, males show a penalty of $€ 10,296$ with respect to $€ 4,854$ for women.

Distinguishing individuals by parental background (proxied by the highest educational attainment of father or mother recorded in IT-SILC 2005 and coded according to the same three levels considered so far) could prove interesting, as recent studies show that in Italy, in addition to a significant influence on children education, a better background is associated with higher earnings for prime-age workers, even when controlling for the children's education (Franzini and Raitano 2009). Table 5 shows that for all levels of parental background the youngest cohort has reduced earnings as compared with the oldest cohort, suggesting that a better parental background does not help mitigate earnings deterioration. Interestingly, the cumulate difference is highest for individuals with a parental background coming midway, while the earning gaps are similar among the children of high and low educated parents.

\section{Tables 5 here}

\subsection{A different proxy of skills: RIF estimates of earnings percentiles}

As noted in section 4, unconditional quantile regressions provide an alternative way to capture differences in skills across individuals, i.e. individuals located at different percentiles of the unconditional annual earnings distribution. As for the OLS regressions, the unconditional quantile regressions include cohort dummies, a third polynomial in labour market experience, education, gender, regional dummies, third polynomial in unemployment rate and in national GDP growth.

Figure $5 \mathrm{~A}-5 \mathrm{C}$ provides the estimated trends of the $10^{\text {th }}, 50^{\text {th }}$ and $90^{\text {th }}$ percentiles, using the coefficients for cohort dummies and experience. Table 6 also includes the estimated value for the first and the last year and the cumulative difference of the second and third cohort with respect to the first, also showing the values of the $25^{\text {th }}$ and $75^{\text {th }}$ percentiles. ${ }^{15}$

Interestingly, for the $10^{\text {th }}$ percentile of the distribution (Figure $5 \mathrm{~A}$ ), the yearly entry earnings are fairly stable across cohorts, as well as the experience profile. This confirms that for unskilled workers there are no differences across cohorts, i.e. individuals belonging to the most recent cohorts have not been penalized.

\footnotetext{
15 Note that the trend of the experience profiles of the $25^{\text {th }}$ and $75^{\text {th }}$ percentiles are similar to the trend of the $10^{\text {th }}$ percentile and $90^{\text {th }}$ percentiles, respectively. Detailed results are available upon request.
} 
Differences across cohorts begin to emerge at median earnings (Figure 5B), since, compared to the first cohort, the most recent cohorts display much lower entry earnings (around 15\%), with the second cohort in an intermediate position. Such differences diminish along the experience profile, although the curves never cross. When considering the cumulative differences along the six years of experience it turns out that the two youngest cohorts display a substantial gap compared to the oldest one, respectively $€ 6,413$ and $€ 11,231$; Table 6).

At the $90^{\text {th }}$ percentile (Figure 5C), the differences across cohorts are very considerable both at the beginning of the career and along the experience path, entailing a cumulative gap of the second and third cohort with respect to the first amounting to $€ 18,656$ and $€ 35,637$, respectively (Table 6). ${ }^{16}$ The latter figure is indeed striking, especially when considering that the entry yearly earnings of an individual of the last cohort at the $90^{\text {th }}$ percentile is around $€$ 20,300: the cumulative loss in six year is, then, 1.75 times the entry earnings. Note also that the cumulative difference at the $90^{\text {th }}$ percentile is basically the same as the one derived for tertiary graduates. Thus the evidence using unconditional quantile regressions shows that considering a different measure of skills, i.e. the percentile of the unconditional distribution of wages, generates patterns across cohorts that are quite similar to those obtained by using the levels of education, confirming the appreciable robustness of our interpretation in terms of skills .

\section{Figures 5A-5C here}

\section{Table 6 here}

\section{Discussion and conclusions}

Our findings show that the labour market conditions of young workers have deteriorated across cohorts in Italy, consistently with previous papers in the literature for other countries. The original contribution of our paper lies in the finding that the deterioration across cohorts is much more marked for skilled individuals, i.e. it is "the best of youth" that have suffered the most. An interesting additional remark concerns the fact that due to some data limitations, in this paper we focus on employees only. As we have seen, the parasubordinate arrangements introduced by the labour market reforms of the '90s are usually characterized by low wages and high unemployment risks, mainly for the tertiary graduated. Hence, the labour market

\footnotetext{
${ }^{16}$ Note that the slope of the experience profiles decreases along the earning distribution. This is mainly due to the fact that the entry earnings across percentiles differ (while in the graph they are set at one for all percentiles), being much greater in the upper tail of the earnings distribution. For instance, for the youngest cohort the entry annual gross earnings at the $10^{\text {th }}$ percentile, at the median, and at the $90^{\text {th }}$ percentile come to $€ 4,360, € 12,320$ and $€ 20,300$ respectively.
} 
performance of the high skilled in the youngest cohorts is likely to be worse than appears in this paper.

What explanation could there be for this deterioration for the youngest cohort, and especially for skilled individuals?

One possible explanation could emerge from standard supply and demand considerations. In the last few decades educational attainment has shown a general increase in Italy, as in all countries. For instance, the share of graduates has increased from around $5 \%$ in the eighties to almost $15 \%$ in recent years. Given this state of affairs, one might argue that the deterioration for the youngest cohort has been worse for the high skilled since these workers have become far less scarce in the economy. Or to put it another way, in accordance with the skill biased technological change literature, it could be argued that the demand for skills in Italy has increased at a lower rate with respect to the supply, thereby determining a reduction in wages for young skilled workers. This is a possible explanation, but it needs stressing that Italy is a country where educational levels are very low with respect to other European and OECD countries, and catching up only very slowly. Arguing that there is simply too much higher education in Italy would also imply that the Italian production system has some peculiar features to the effect that the demand for skills is much lower than in other European/OECD countries.

Another possible explanation lies in the institutional changes that have occurred in the last few decades in Italy, where a partial and targeted labour market deregulation process has been underway (Esping Andersen and Regini 2000). The hypothesis that an increase in flexibility could have entailed a reduction in bargaining power for young individuals is perfectly reasonable and plausible, since new temporary contracts introduced by the reforms have been used mainly for young people. Another important step in this explanation is to understand why the decrease in bargaining power has been greater for skilled individuals. This might be accounted for with the fact that new forms of temporary contracts have been used for graduates on a very large scale (Barbieri and Scherer 2009), and this in turn could have been due to a difficulty for Italian labour demand to absorb the increasing share of graduates on regular contracts, associated with higher wages.

Finally, it might also be a matter of the quality of education. The Italian university system was reformed in the nineties, and one might argue that the quality of skilled individuals declined over time, thus accounting for the reduction of wages for recent cohorts as well as the fall in educational wage premia. 
Identification of all the factors at work behind our results is far beyond the goal of this paper, also because it would require different data for different explanations. This will be the focus of future research. 


\section{References}

Barbieri P., Scherer S. (2009), "Labour Market Flexibilisation and its Consequences in Italy", European Sociological Review, vol. 3, pp. 677-692.

Beach C.M., Finnie R. (2004), "A Longitudinal Analysis of Earnings Change in Canada", The Canadian Journal of Economics, vol. 37, pp. 219-240.

Beaudry P. and D. A. Green (2000), “Cohort Patterns in Canadian Earnings: Assessing the Role of Skill Premia in Inequality Trends", The Canadian Journal of Economics, v. 33 pp. 907-936.

Berton F., Richiardi M., Sacchi S. (2012), “The Political Economy of Work Security and Flexibility. Italy in Comparative Perspective", The Policy Press.

Blanchard, O. and A. Landier (2002), "The Perverse Effects Of Partial Labour Market Reform: Fixed-Term Contracts In France," Economic Journal, 112(480), F214-F244

Blossfeld H.P., Klijzing E., Mills M., Kurz K. (eds), (2005), Globalization, Uncertainty and Youth in Society, Routledge.

Blossfeld H.P., Bucholz S., Bukodi E., Kurz K. (eds), (2008), Globalization and the Labor Market: Comparing Early Working Life in Eleven Countries, Edward Elgar.

Booth A., Francesconi M., Frank J. (2002). “Temporary jobs: Stepping stones or deadends?”, Economic Journal, vol. 112.

Brandolini A., P. Cipollone, Sestito P. (2001), "Earnings dispersion, low pay and household poverty in Italy, 1977-1998", Temi di Discussione Banca d'Italia, n. 427.

Bukodi E., Ebralidze E., Schmeher P., Blossfeld H.P. (2008), "Struggling to become an insider: does increasing flexibility at labor market entry affect early careers? A theoretical framework", in Blossfeld H.P., Bucholz S., Bukodi E., Kurz K. (eds), Globalization and the Labor Market: Comparing Early Working Life in Eleven Countries, Edward Elgar.

Card D. and T. Lemieux (2001), "Can Falling Supply Explain the Rising Return to college for Younger Men? A Cohort Based Analysis", The Quarterly Journal of Economics, v. 66 pp. $705-$ 746.

Esping Andersen G., Regini M. (eds.), (2000), Why Deregulate Labour Markets?, Oxford University Press.

EUROSTAT (2009), Youth in Europe. A Statistical Portrait, Luxembourg.

Fitzenberg B., R. Hujer, T. E. MaCurdy and R. Schnabel (2001), "Testing for uniform wage trends in West-Germany: A cohort analysis using quantile regressions for censored data", Empirical Economics, v. 26, pp. 41-86.

Firpo, S., Fortin, N.M., Lemieux, T. (2009), “Unconditional Quantile Regressions", Econometrica, vol. 77, pp. 953-973.

Franzini M., Raitano M. (2009), "Persistence of inequality in Europe: the role of family economic conditions", International Review of Applied Economics, vol. 23, n. 3.

Gosling A, Machin S, Meghir C. 2000, "The changing distribution of male wages in the U.K", Review of Economic Studies, vol. 67, pp. 635-666.

Hampel F. R. (1974): "The Influence Curve and Its Role in Robust Estimation," Journal of the American Statistical Association, Vol. 60, pp. 383-393.

Katz L., Autor D. (1999), "Changes in the wage structure and earnings inequality" in Ashenfelter O., Card D. (eds), Handbook of Labor Economics, vol. 3, pp. 1463-1555 Elsevier.

Koenker R., Basset G. (1978), “Regression Quantiles”, Econometrica, Vol. 46, No. 1., pp. 33-50. 
Mishel L. (2012), “Entry-Level Workers' Wages Fell in Lost Decade”, Economic Policy Institute, n. 327.

Naticchioni, P. Ricci, A, Rustichelli, E. (2010), “Far from a skill-biased change: falling educational wage premia in Italy", Applied Economics, 2010, Vol.42 (26), 3383-3400.

OECD (1994), Jobs Study, Paris.

Raitano M. (2012), “La distribuzione delle retribuzioni da lavoro dipendente in Italia nel periodo 1996-2009: l'evidenza dal campione AD-SILC", Economia e Lavoro, n.3/2012.

Rosolia A., Torrini R. (2007), "The Generation Gap: Relative Earnings of Young and Old Workers in Italy", Temi di discussione Banca d'Italia, n. 639.

Rosolia A., Torrini R. (2013), "The Generation Gap: New Evidence", presented at the 5th ECINEQ Conference, 22-24/7/2013, Bari.

Schizzerotto A., Trivellato U., Sartor N. (eds), (2011), Generazioni disuguali. Le condizioni di vita dei giovani di ieri e di oggi: un confronto, Il Mulino, Bologna. 


\section{Figures}

Figure 1: Average annual gross earnings by birth cohort
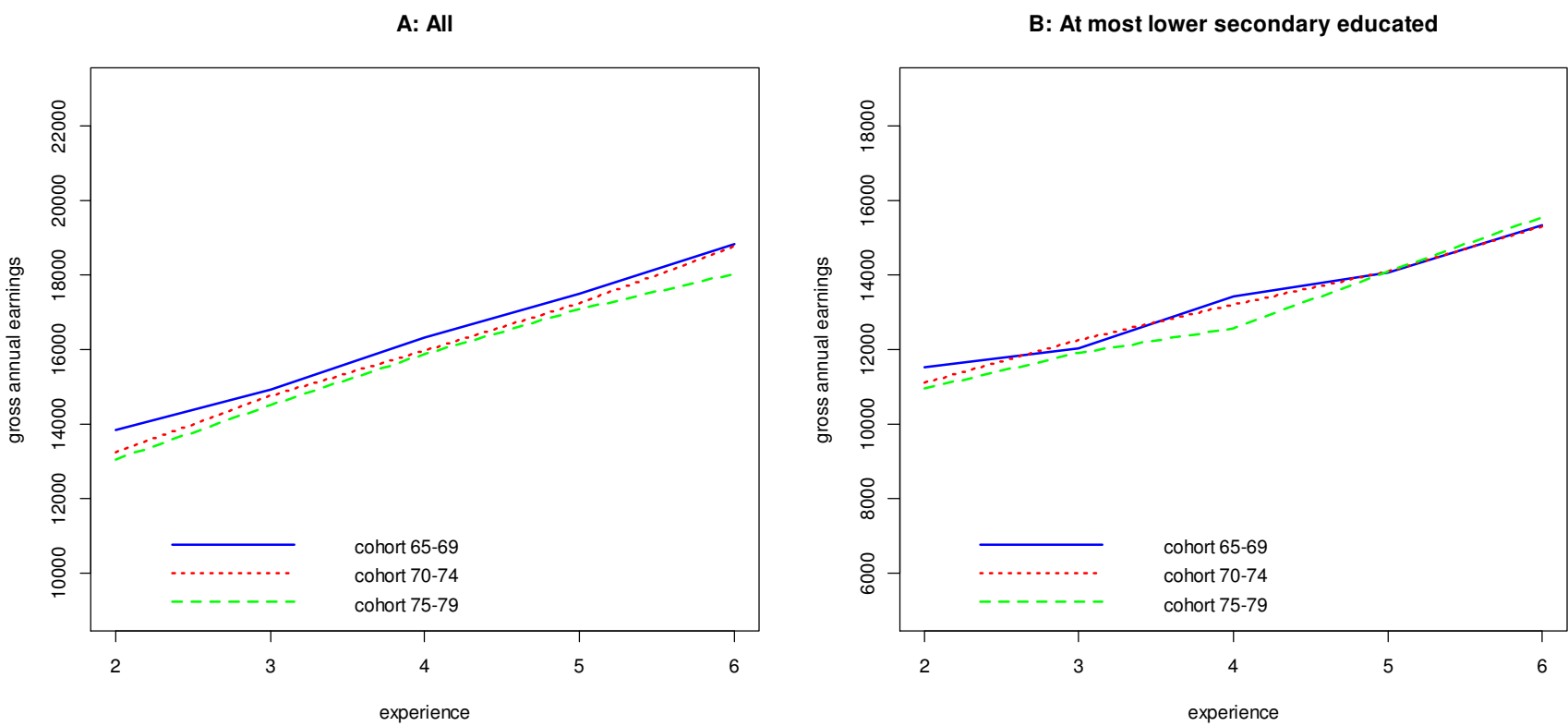

C: Upper secondary educated

D: Tertiary educated
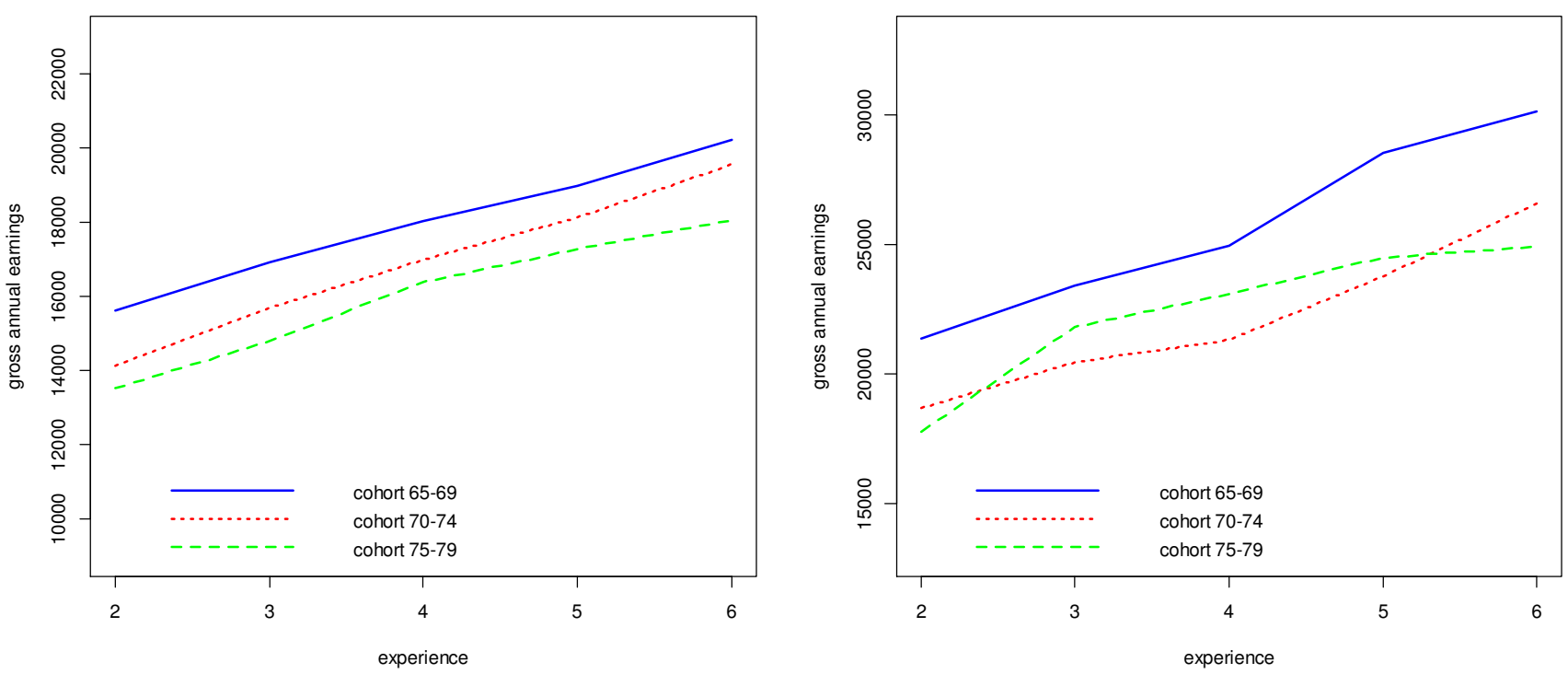
Figure 2: OLS estimates of gross annual earnings by birth cohort

A: All

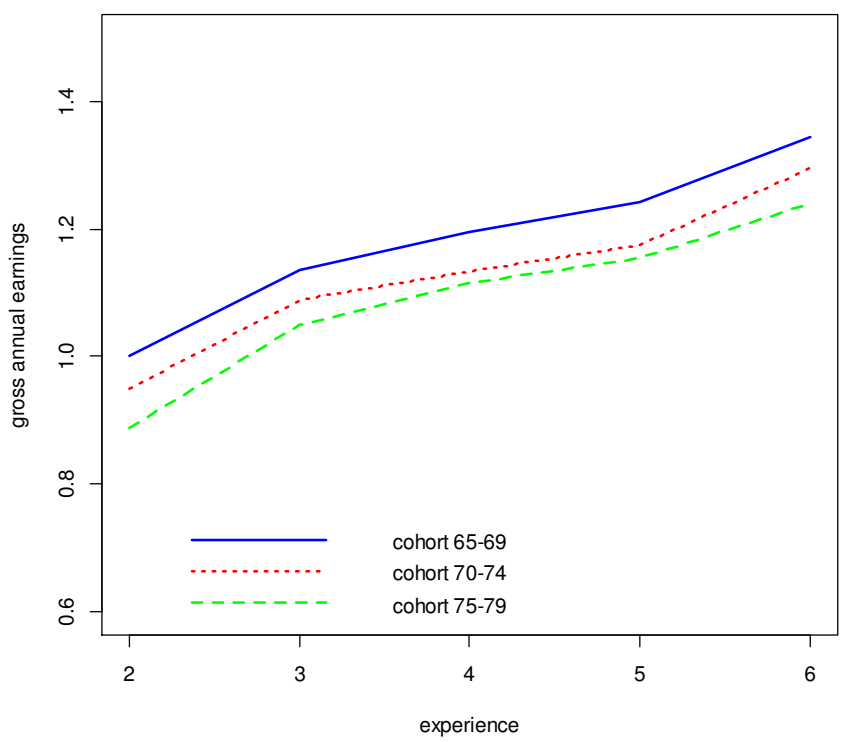

C: Upper secondary educated

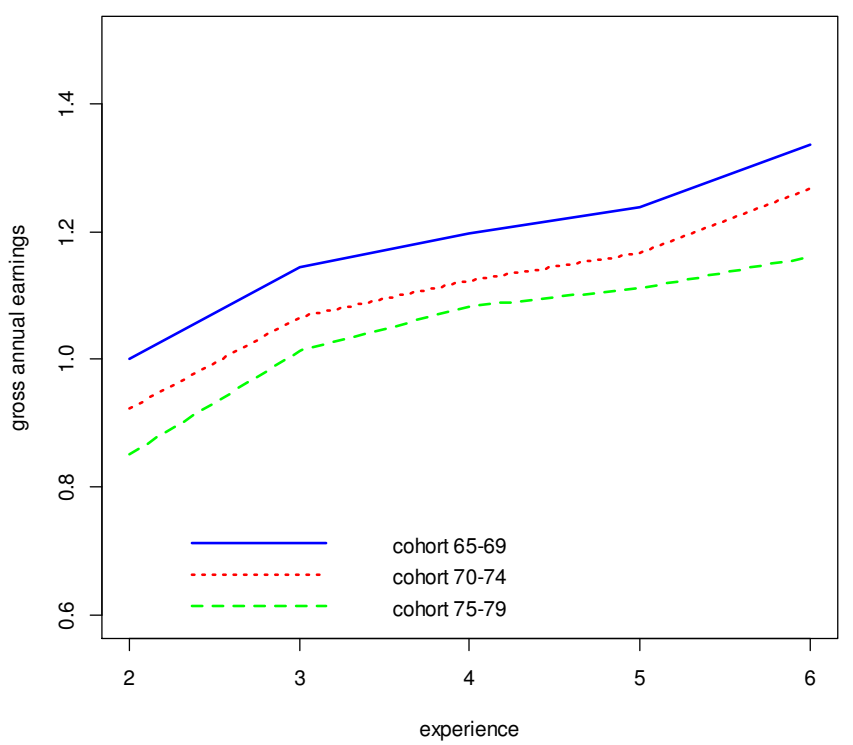

B: At most lower secondary educated

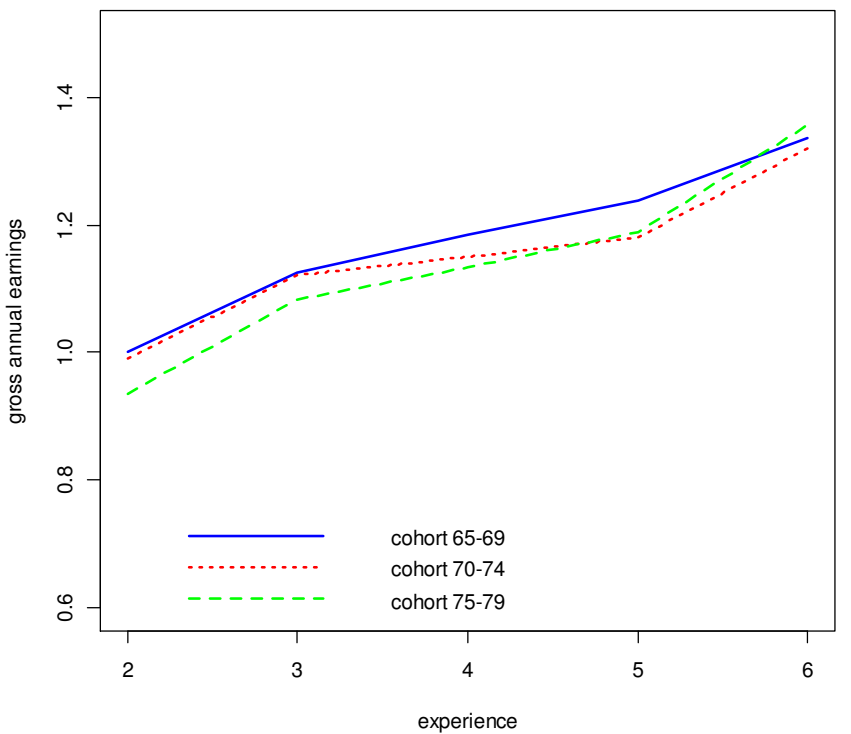

D: Tertiary educated

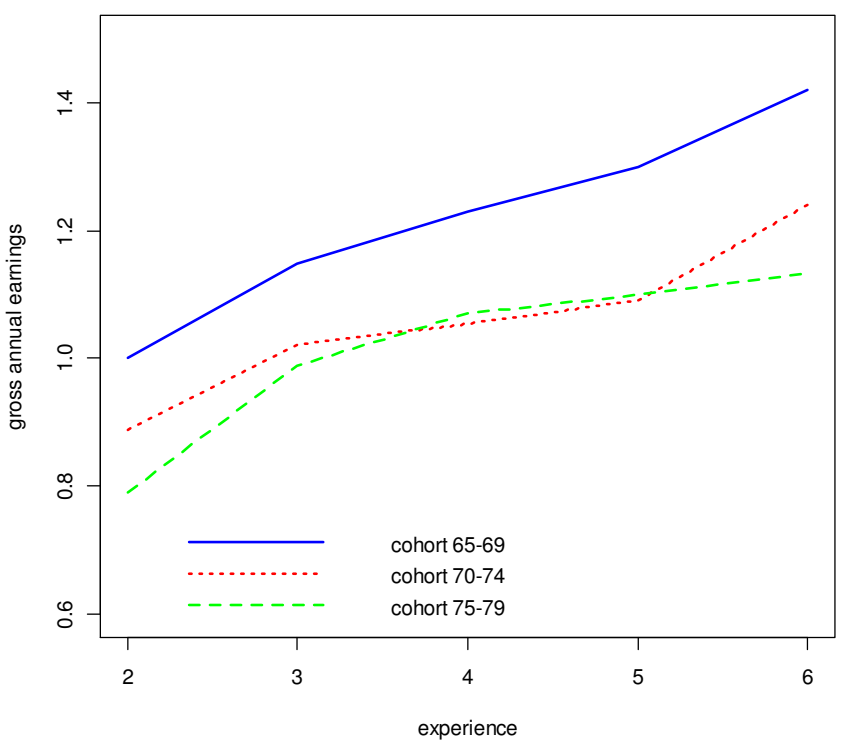


Figure 3: Educational wage premia in the first 6 years of career (\% values)

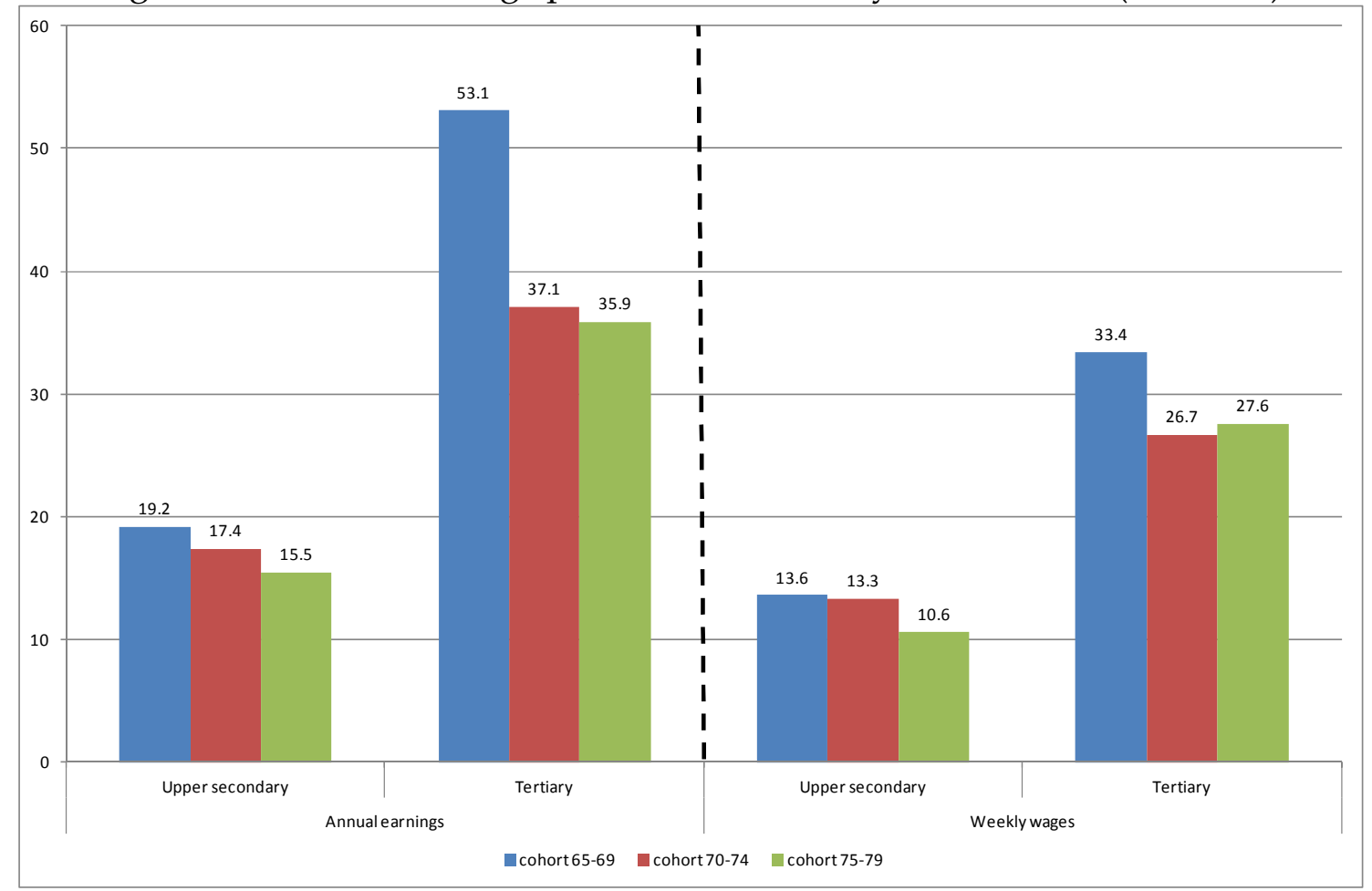


Figure 4: OLS estimates of gross weekly wages by birth cohort

A: All

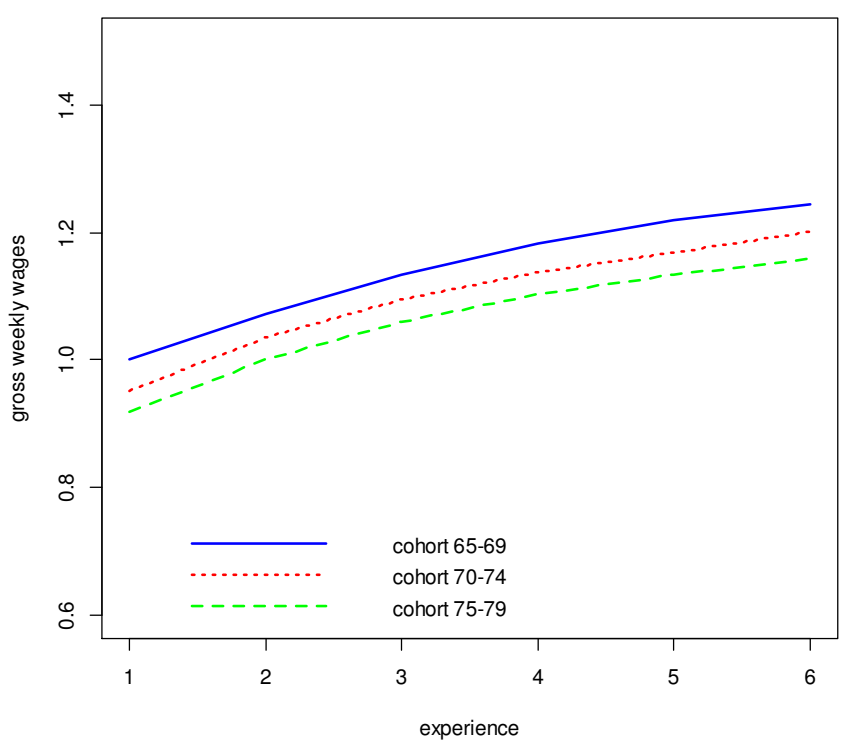

C: Upper secondary educated

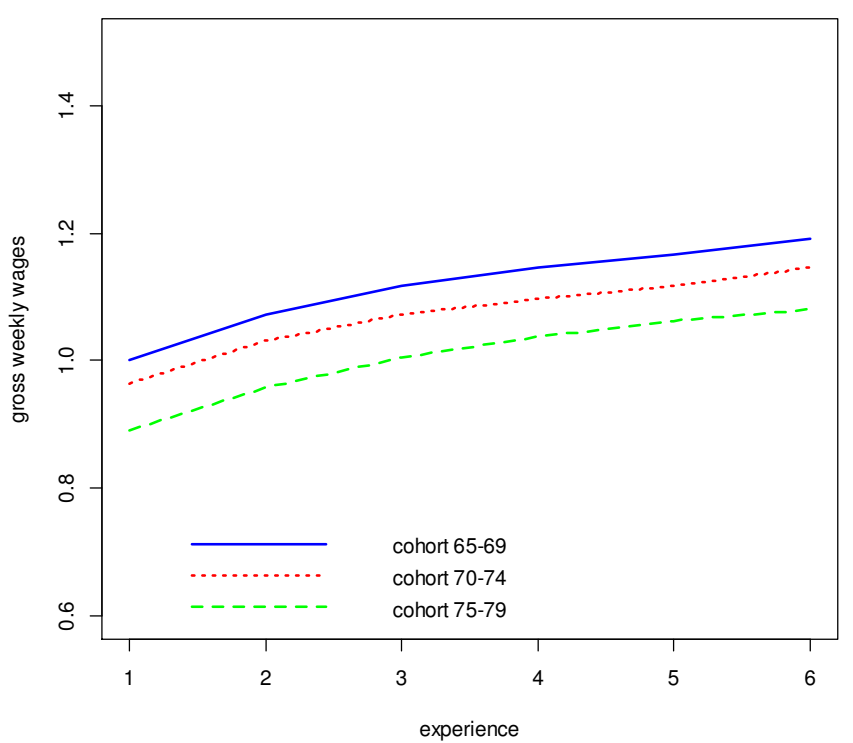

B: At most lower secondary educated

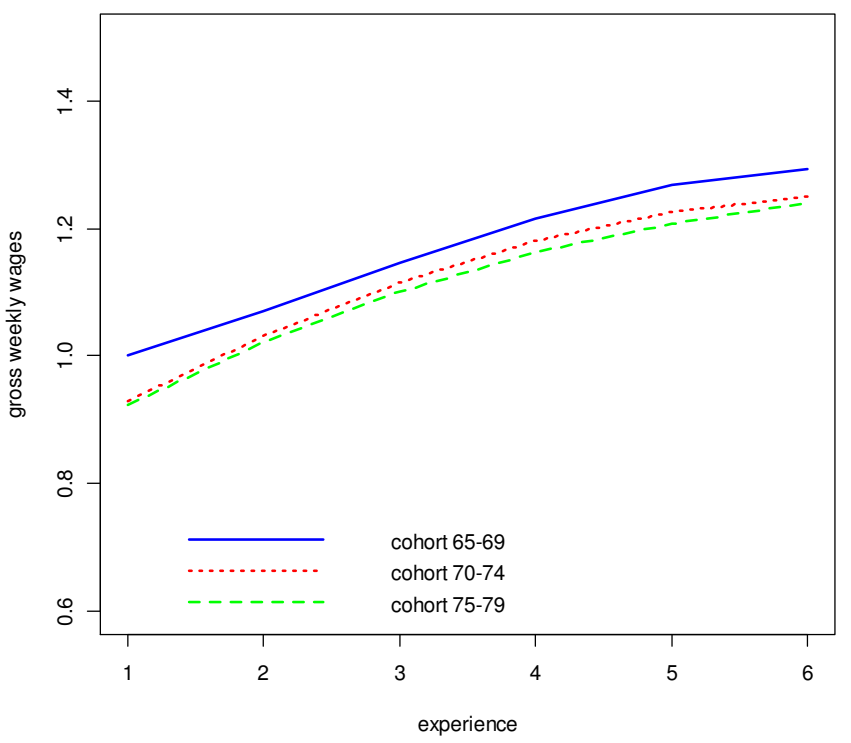

D: Tertiary educated

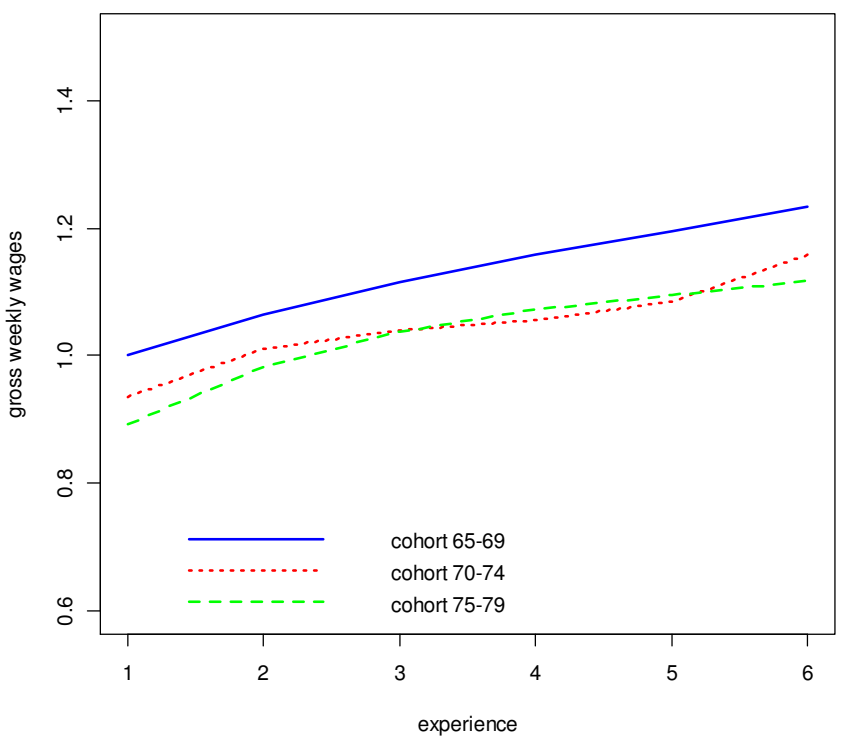


Figure 5: RIF estimates of gross annual earnings by birth cohort

A: P10

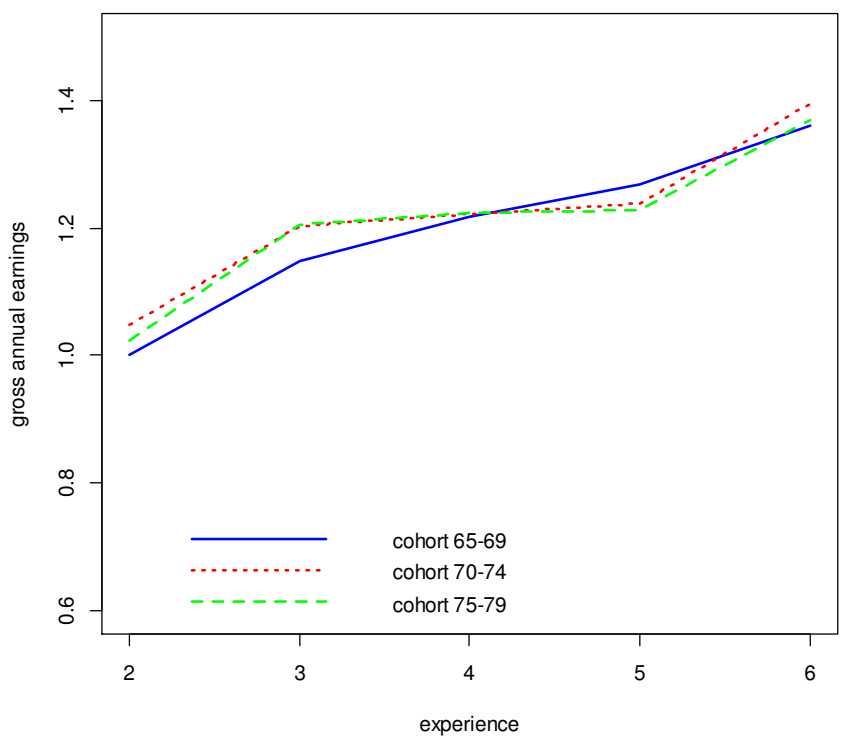

C: P90

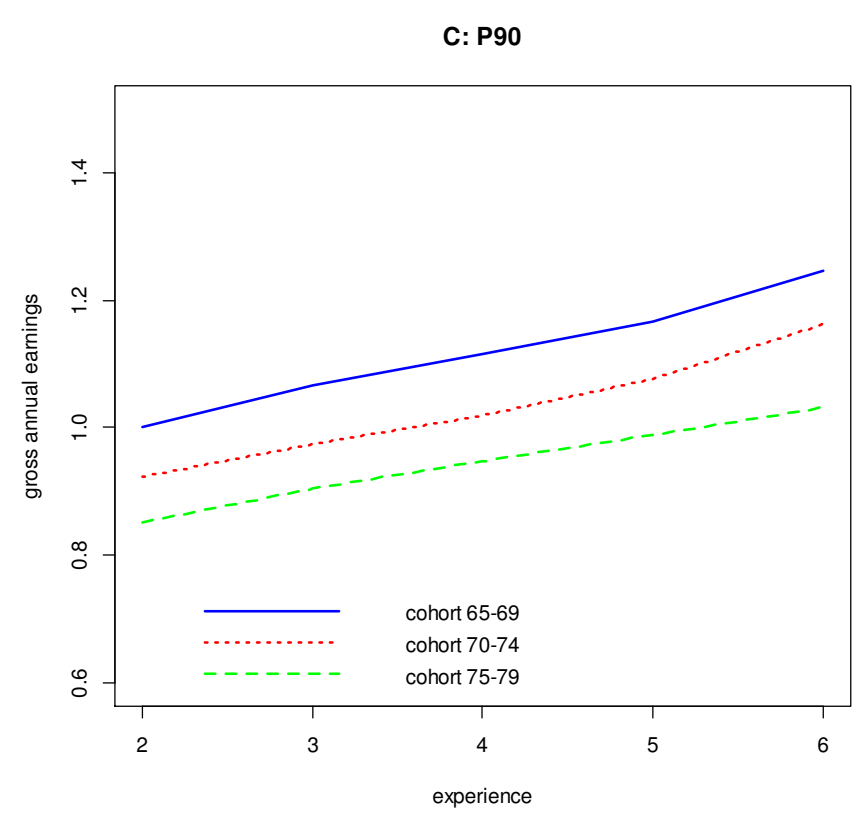

B: P50

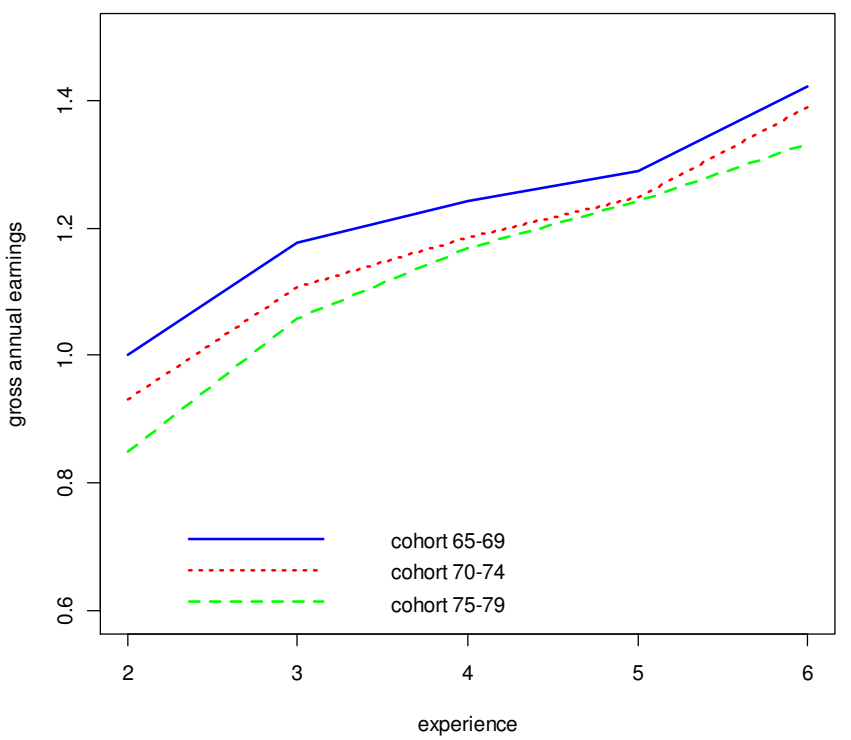




\section{Tables}

Tab. 1: Real annual gross earnings (Euros 2010).

\begin{tabular}{ll|cc|c|}
\hline & & \multicolumn{2}{|c|}{ Experience } & \multirow{2}{*}{$\begin{array}{c}\text { Cumulate } \\
\text { difference (with } \\
\text { Cohort 65-69) }\end{array}$} \\
\hline \multirow{3}{*}{ All individuals } & Cohort 65-69 & 2 & 6 & -- \\
& Cohort 70-74 & 13,844 & 18,820 & $-1,441$ \\
& Cohort 75-79 & 13,224 & 18,767 & $-2,853$ \\
\hline \multirow{3}{*}{ At most lower secondary } & Cohort 65-69 & 11,517 & 18,035 & -- \\
& Cohort 70-74 & 11,094 & 15,350 & -451 \\
& Cohort 75-79 & 10,944 & 15,551 & $-1,319$ \\
\hline \multirow{3}{*}{ Upper secondary } & Cohort 65-69 & 15,609 & 20,219 & -- \\
& Cohort 70-74 & 14,127 & 19,551 & $-5,270$ \\
\hline \multirow{3}{*}{ Tertiary } & Cohort 75-79 & 13,524 & 18,050 & $-9,744$ \\
\hline & Cohort 65-69 & 21,348 & 30,138 & -- \\
& Cohort 70-74 & 18,673 & 26,599 & $-17,624$ \\
& Cohort 75-79 & 17,751 & 24,914 & $-16,356$ \\
\hline
\end{tabular}

Source: computations on AD-SILC data

Tab. 2: OLS estimates on annual gross earnings. Relative values at starting and final years and difference in cumulate earnings respect to the first cohort

\begin{tabular}{|c|c|c|c|c|}
\hline & & \multicolumn{2}{|c|}{ Experience } & \multirow{2}{*}{$\begin{array}{l}\text { Cumulate } \\
\text { difference } \\
\text { (euro 2010) }\end{array}$} \\
\hline & & 2 & 6 & \\
\hline \multirow{3}{*}{ All individuals } & Cohort 65-69 & 1.000 & 1.344 & -- \\
\hline & Cohort 70-74 & 0.950 & 1.296 & $-4,866$ \\
\hline & Cohort 75-79 & 0.888 & 1.240 & $-8,133$ \\
\hline \multirow{3}{*}{ At most lower secondary } & Cohort 65-69 & 1.000 & 1.337 & -- \\
\hline & Cohort 70-74 & 0.991 & 1.320 & $-2,076$ \\
\hline & Cohort 75-79 & 0.936 & 1.357 & $-2,800$ \\
\hline \multirow{3}{*}{ Upper secondary } & Cohort 65-69 & 1.000 & 1.336 & -- \\
\hline & Cohort 70-74 & 0.922 & 1.267 & $-9,100$ \\
\hline & Cohort 75-79 & 0.851 & 1.160 & $-16,743$ \\
\hline \multirow{3}{*}{ Tertiary } & Cohort 65-69 & 1.000 & 1.419 & -- \\
\hline & Cohort 70-74 & 0.888 & 1.239 & $-28,973$ \\
\hline & Cohort 75-79 & 0.791 & 1.134 & $-35,534$ \\
\hline
\end{tabular}

Source: computations on AD-SILC data 
Tab. 3: OLS estimates on weekly gross wages. Relative values at starting and final years and mean weekly wage difference with respect to the first cohort

\begin{tabular}{|c|c|c|c|c|}
\hline & & \multicolumn{2}{|c|}{ Experience } & \multirow{2}{*}{$\begin{array}{c}\text { Mean difference in } \\
\text { weekly wages } \\
\text { (euro 2010) }\end{array}$} \\
\hline & & 1 & 6 & \\
\hline \multirow{3}{*}{ All individuals } & Cohort 65-69 & 1.000 & 1.245 & -- \\
\hline & Cohort 70-74 & 0.951 & 1.201 & -18.2 \\
\hline & Cohort 75-79 & 0.918 & 1.158 & -32.5 \\
\hline \multirow{3}{*}{ At most lower secondary } & Cohort 65-69 & 1.000 & 1.294 & - \\
\hline & Cohort 70-74 & 0.929 & 1.250 & -19.1 \\
\hline & Cohort 75-79 & 0.922 & 1.240 & -24.8 \\
\hline \multirow{3}{*}{ Upper secondary } & Cohort 65-69 & 1.000 & 1.191 & -- \\
\hline & Cohort 70-74 & 0.964 & 1.146 & -23.4 \\
\hline & Cohort 75-79 & 0.891 & 1.081 & -56.0 \\
\hline \multirow{3}{*}{ Tertiary } & Cohort 65-69 & 1.000 & 1.234 & -- \\
\hline & Cohort 70-74 & 0.936 & 1.159 & -45.1 \\
\hline & Cohort 75-79 & 0.893 & 1.117 & -52.7 \\
\hline
\end{tabular}

Source: computations on AD-SILC data

Tab. 4: OLS estimates on the ratio between annual earnings and mean earnings of workers aged 35-44. Relative values at starting and final years

\begin{tabular}{ll|cc|}
\hline & & \multicolumn{2}{|c|}{ Experience } \\
& & 2 & 6 \\
All individuals & Cohort 65-69 & 1.000 & 1.178 \\
& Cohort 70-74 & 0.959 & 1.171 \\
& Cohort 75-79 & 0.939 & 1.152 \\
\hline \multirow{3}{*}{ At most lower secondary } & Cohort 65-69 & 1.000 & 1.141 \\
& Cohort 70-74 & 0.966 & 1.140 \\
& Cohort 75-79 & 0.957 & 1.172 \\
\hline \multirow{3}{*}{ Upper secondary } & Cohort 65-69 & 1.000 & 1.185 \\
& Cohort 70-74 & 0.958 & 1.176 \\
\hline \multirow{3}{*}{ Tertiary } & Cohort 75-79 & 0.933 & 1.130 \\
& Cohort 65-69 & 1.000 & 1.410 \\
\hline Source: computat & 1.277 \\
\hline
\end{tabular}

Source: computations on AD-SILC data 
Tab. 5: OLS estimates of annual earnings by gender and parental background. Relative values at starting and final years and difference in cumulate earnings respect to the first cohort

\begin{tabular}{|c|c|c|c|c|}
\hline & & \multicolumn{2}{|c|}{ Experience } & \multirow{2}{*}{$\begin{array}{c}\text { Cumulate } \\
\text { difference } \\
\text { (euro 2010) }\end{array}$} \\
\hline & & 2 & 6 & \\
\hline \multirow{3}{*}{ Males } & Cohort 65-69 & 1.000 & 1.380 & -- \\
\hline & Cohort 70-74 & 0.942 & 1.344 & $-5,980$ \\
\hline & Cohort 75-79 & 0.868 & 1.271 & $-10,296$ \\
\hline \multirow{3}{*}{ Females } & Cohort 65-69 & 1.000 & 1.293 & -- \\
\hline & Cohort 70-74 & 0.963 & 1.240 & $-3,079$ \\
\hline & Cohort 75-79 & 0.917 & 1.210 & $-4,854$ \\
\hline \multirow{3}{*}{ Parents at most lower secondary educated } & Cohort 65-69 & 1.000 & 1.336 & -- \\
\hline & Cohort 70-74 & 0.947 & 1.286 & $-4,670$ \\
\hline & Cohort 75-79 & 0.898 & 1.231 & $-7,180$ \\
\hline \multirow{3}{*}{ Parents upper secondary educated } & Cohort 65-69 & 1.000 & 1.374 & - \\
\hline & Cohort 70-74 & 0.930 & 1.325 & $-7,950$ \\
\hline & Cohort 75-79 & 0.824 & 1.233 & $-13,922$ \\
\hline \multirow{3}{*}{ Parents tertiary educated } & Cohort 65-69 & 1.000 & 1.565 & -- \\
\hline & Cohort 70-74 & 1.071 & 1.374 & $-2,763$ \\
\hline & Cohort 75-79 & 0.973 & 1.378 & $-7,822$ \\
\hline
\end{tabular}

Source: computations on AD-SILC data

Tab. 6: RIF estimates of annual gross earnings. Relative values at starting and final years and difference in cumulate earnings respect to the first cohort

\begin{tabular}{cc|cc|c|}
\hline & & \multicolumn{2}{|c|}{ Experience } & \multirow{2}{*}{$\begin{array}{c}\text { Cumulate difference } \\
\text { (euro 2010) }\end{array}$} \\
\cline { 1 - 3 } P10 & Cohort 65-69 & 1.000 & 6 & -- \\
& Cohort 70-74 & 1.048 & 1.360 & 672 \\
& Cohort 75-79 & 1.023 & 1.395 & 300 \\
\hline \multirow{3}{*}{ P25 } & Cohort 65-69 & 1.000 & 1.369 & -- \\
& Cohort 70-74 & 1.007 & 1.462 & -143 \\
& Cohort 75-79 & 0.964 & 1.458 & 209 \\
\hline \multirow{3}{*}{ P50 } & Cohort 65-69 & 1.000 & 1.457 & -- \\
& Cohort 70-74 & 0.931 & 1.422 & $-6,413$ \\
& Cohort 75-79 & 0.849 & 1.389 & $-11,231$ \\
\hline \multirow{3}{*}{ P75 } & Cohort 65-69 & 1.000 & 1.332 & -- \\
& Cohort 70-74 & 0.949 & 1.255 & $-9,499$ \\
\hline \multirow{3}{*}{ P90 } & Cohort 75-79 & 0.890 & 1.191 & $-16,320$ \\
& Cohort 65-69 & 1.000 & 1.147 & -- \\
& Cohort 70-74 & 0.922 & 1.247 & $-18,656$ \\
\hline
\end{tabular}

Source: computations on AD-SILC data 